\title{
ADVANCED EXERGY ANALYSIS OF AN ORGANIC RANKINE CYCLE WASTE HEAT RECOVERY SYSTEM OF A MARINE POWER PLANT
}

\author{
Turgay Koroglu ${ }^{1, *}$, Oguz Salim Sogut ${ }^{1}$ \\ Keywords: Marine Power Plant, Combined Cycle, Organic Rankine Cycle, Advanced Exergy \\ Analysis
}

\begin{abstract}
Energy efficiency has a great importance to reduce both fuel consumption and greenhouse gas emissions, which are the most important focus points for researchers in maritime industry. Exergy analysis, which is widely used to design, analyze and evaluate thermal energy systems, plays an important role to increase energy efficiency. It reveals destruction of available energy in components and leads the researcher to achieve better engineering and systems. Advanced exergy analysis has the capability to reveal the interconnections among system components and improvement potential of inspected components and also the overall system.

Steam cycle is used in ships as main or auxiliary power production means for a long time. Also, it is used to recover waste heat from high temperature exhaust gases. Organic rankine cycle (ORC) is an alternative energy recovery strategy to utilize relatively low temperature heat sources to produce power. Usage of ORC in marine power plants is relatively new field to explore.

In this paper, a marine power plant with ORC is investigated. Energy and exergy analyses have been carried out to identify conditions and parameters that affect the efficient operation of the system. Then, a parametric study has been conducted to determine the optimum range of operation for power plant and ORC considering different load conditions. Finally, exergy destruction of each component is calculated to give further insight information about the potential of improvement for the efficient operation.
\end{abstract}

\section{INTRODUCTION}

Anthropogenic emissions are tending to increase more and more in recent years [1]. Among all sectors that emit GHGs, seaborne trade has around 3.1\% share of these emissions [2]. Besides that, fuel prices are rising each year and expected to continue its rising trend in the future [3]. Priorities of ship-owners are to lower costs and emissions of the fleet [4]. Both could be achieved with efficient use of energy. Hence more research work has been carried out on improvement of energy efficiency.

Waste heat recovery (WHR) has a great potential for achieving these priorities [5, 6], and is a good choice due to $85 \%$ of world fleet have two-stroke marine engines [7]. WHR may be expressed as a method to utilize waste heat that is produced by an energy conversion system. Thus, it may be applied mostly to exhaust gas, air cooler and cooling water of marine engines which have enormous heat to be recovered [6]. The highest share of utilizable heat belongs to exhaust gases due to their relatively high temperature, then air cooler and jacket water cooler [8]. Some WHR methods such as organic Rankine cycle (ORC), power turbine, thermoelectric generation, steam cycle, desalination and refrigeration are reviewed in $[6,9,10]$. Among all, ORC is a useful option to recover low-grade heat sources and is based on a Rankine cycle, but working fluid is selected as organic compounds in contrast with water-steam [11]. Detailed information on ORC application of internal combustion engine waste heat recovery could be found in the work of Sprouse III and Depcik [9].

The first and the second laws of thermodynamics together provide a basis to exergy analysis [12], which is already applied to all types of energy systems [13]. However, it is recently applied to ships [14-16] and marine engines (including WHR) [17-19] when compared to other systems.

Advanced exergy analysis is based on conventional exergy analysis with the difference of splitting exergy destruction of investigated component [20]. It is first suggested and later developed on the idea of TJ Kotas [21]. Recently, an advanced exergy analysis has been carried out on the ships and marine energy systems [22]. 
In this paper, energy, exergy and advanced exergy analyses of an organic Rankine cycle placed after a typical five-cylinder two-stroke low speed marine diesel engine exhaust boiler have been carried out. Fully loaded ship simulator data is used in analyses. Then, parametric analyses have been performed with respect to lever positions of main engine and working fluids of ORC. Finally, a new definition of exergetic efficiency which is based on advanced exergy analysis is applied to the investigated system [22].

\section{THEORETICAL METHOD}

Exergy is defined as the maximum work potential of a system, which is in interaction with reference environment [13]. Each exergy for stream $j, E \dot{E}$, may be defined as follows with neglecting potential and kinetic exergies [12]:

$$
\dot{E x_{J}} \cong \dot{m}_{j}\left[\left(h_{j}-h_{0}\right)-T_{0}\left(s_{j}-s_{0}\right)\right]
$$

where, $\dot{m}, h, T, s$, and subscript 0 , denote mass flow rate, enthalpy, temperature, entropy and reference environment condition respectively. Exergy balance, exergy efficiency and exergy destruction ratio of $k$ th component may be expressed as [12]:

$$
\begin{aligned}
& \dot{E} x_{D, k}=\dot{E} x_{F, k}-\dot{E} x_{P, k} \\
& \varepsilon_{k}=\frac{\dot{E} x_{P, k}}{\dot{E} x_{F, k}} \\
& y_{D, k}^{*}=\frac{\dot{E} x_{D, k}}{E x_{D, t o t}} \\
& \dot{E} x_{D, t o t}=\sum_{k} \dot{E} x_{D, k}
\end{aligned}
$$

where $\dot{E} x_{F, k}$ exergy rate of fuel, $\dot{E} x_{P, k}$ exergy rate of product, $\dot{E} x_{D, k}$ exergy destruction rate, $\varepsilon_{k}$ exergy efficiency, $y_{D, k}^{*}$ exergy destruction ratio of the $k$ th component among all and $E x_{D, t o t}$ total exergy destruction rate of overall system. Exergy analysis is an eligible tool to define sources, location and magnitude of irreversibilities and compare systems [20]. Nonetheless, it is not useful when the real improvement potential needed to optimize the system [21]. Hence, advanced exergy analysis introduced to cover the needs that cannot be addressed by conventional exergy analysis.

In his 1985 book, Kotas proposed an approach to define unavoidable part of exergy destruction which he called "intrinsic irreversibility rate" by defining the possible minimum irreversibility rate within the limits of physical, technological, economic and other constraints [21]. The difference between actual and unavoidable exergy destruction rates is avoidable part of exergy destruction and named by him as "avoidable irreversibility rate" [21]. It can be formulated as [21, 23]:

$$
\dot{E} x_{D, k}^{A V}=\dot{E} x_{D, k}-\dot{E} x_{D, k}^{U N}
$$

where, $E x_{D, k}^{A V}$ is the avoidable part and $\dot{E} x_{D, k}^{U N}$ is the unavoidable part of exergy destruction of $k$ th component. Unavoidable part of exergy destruction for $k$ th component could be calculated in a created cycle where all components are in their unavoidable conditions [20, 24].

Recently, a new exergetic efficiency for $k$ th component, $\varepsilon_{k}^{+}$, on the basis of advanced exergy analysis is defined $[22,25]$ :

$$
\varepsilon_{k}^{+}=\frac{\dot{E} x_{P, k}}{\dot{E x_{F, k}}-\dot{E} x_{D, k}^{A V}}
$$

The intention is to observe effect of advanced exergy analysis and the improvement potential of $k$ th component. It is based on a simple fact that, efficiency is the ratio of desired output to required input [26]. In a 
designed system, desired output is constant, hence improvement must directly influence to the required input. Therefore, this new advanced exergetic efficiency is introduced [22,25]. Further, avoidable exergy destruction rate could be evaluated as a sort of fuel saving potential of $k$ th component.

Finally, energy efficiency is defined as the ratio of net power output to total heat input as in [26]:

$$
\eta_{T h}=\frac{\dot{W}_{t o t}}{\dot{Q}_{t o t}}
$$

\section{SYSTEM MODEL DESCRIPTION}

The system model has three parts namely exhaust system stack, main engine jacket cooling water system and closed organic rankine cycle. Exhaust exits main engine and enters turbocharger. Then, it goes into exhaust boiler to generate superheated steam for steam turbine. After that, exhaust gas heats up domestic hot water in evaporator and economizer, which are parts of the exhaust boiler. Hence there is already a waste heat recovery system on the investigated ship. But, exhaust stack temperature is relatively high to recover heat with organic rankine cycle, which is located after economizer of exhaust boiler.

ORC in the exhaust system has its own economizer, evaporator with pump and drum, and superheater. Organic rankine cycle includes pump, preheater, regenerator, exhaust system shared parts, turbine and condenser. Organic fluid is pumped, heated in preheater by main engine jacket water, and also in regenerator by superheated organic fluid vapor after turbine. Then, it enters economizer and gets heated by exhaust gas until it saturates. Evaporator takes saturated fluid and turns it into saturated vapor by the energy of exhaust gases. Superheater, generates superheated vapor which was saturated vapor coming from evaporator. Later, it expands in the turbine and produces power. Expanded vapor gets into regenerator to heat up organic fluid coming from preheater. Condenser condenses the vapor coming from regenerator with the help of seawater and sends condensed fluid to pump to complete the closed cycle. The system model is designed and run in Ebsilon Professional Software [27] and can be seen in Figure 1.

As a starting point, navigational full ahead lever position is selected and all available data have been taken for lever positions of $100 \%, 85 \%, 75 \%$ and $60 \%$. All related data of the ship and main engine could be seen on Tables 1 and 2.

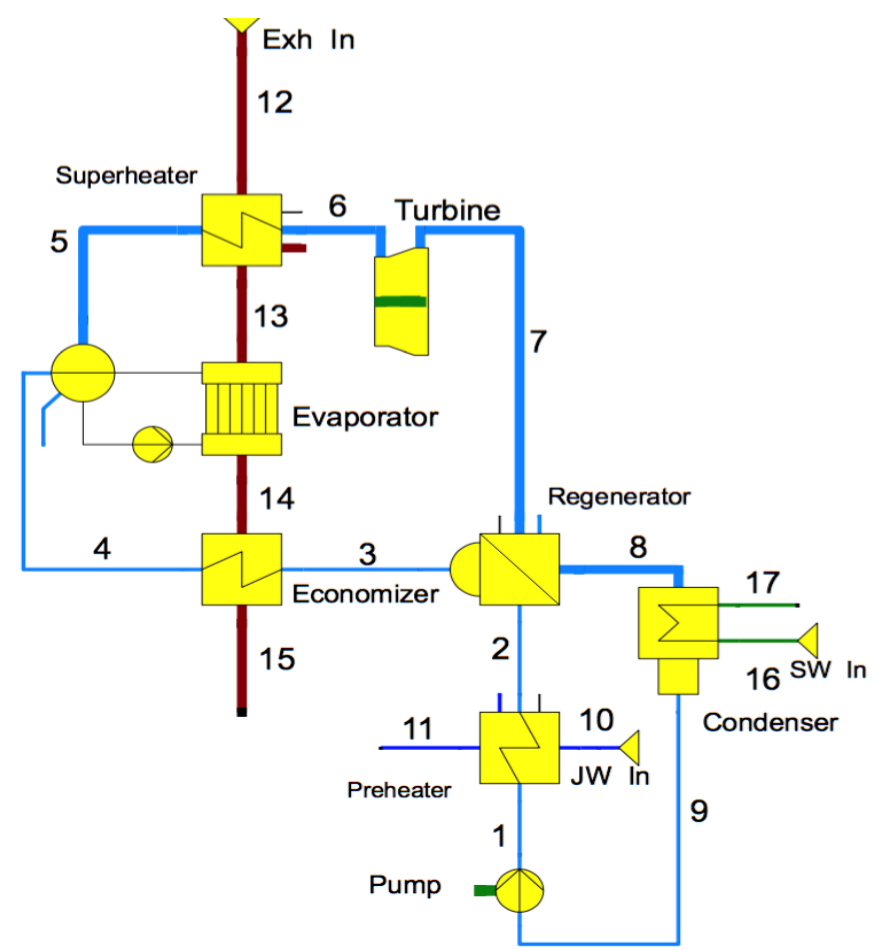

Figure 1. General schematic diagram of ORC system 
Table 1. General information of investigated ship and main engine

\begin{tabular}{llll}
\hline Ship & & Main Engine & \\
\hline \hline Length overall & $305 \mathrm{~m}$ & Cylinder bore & $90 \mathrm{~cm}$ \\
Draught & $19 \mathrm{~m}$ & Stroke & $292 \mathrm{~cm}$ \\
Breadth & $47 \mathrm{~m}$ & MCR Power & $18 \mathrm{MW}$ \\
Depth & $30.4 \mathrm{~m}$ & MCR Engine Speed & $74 \mathrm{RPM}$ \\
Deadweight & 178720 tons & Specific Fuel Consumption & $168 \mathrm{~g} / \mathrm{kWh}$ \\
\hline
\end{tabular}

Table 2. Simulator data used for this study

\begin{tabular}{ccccccccc}
\hline $\begin{array}{c}\text { Ahead } \\
\text { Lever } \\
(\%)\end{array}$ & $\begin{array}{c}\text { Engine } \\
\text { Speed } \\
(\mathrm{RPM})\end{array}$ & $\begin{array}{c}\text { Ship } \\
\text { Speed } \\
(\mathrm{knts})\end{array}$ & $\begin{array}{c}\text { Mean } \\
\text { Effective } \\
\text { Power }(\mathrm{MW})\end{array}$ & $\begin{array}{c}\text { Exh T } \\
\left({ }^{\circ} \mathrm{C}\right)\end{array}$ & $\begin{array}{c}\text { Exh mass } \\
\text { Flow }(\text { ton/h) }\end{array}$ & $\begin{array}{c}\text { JW Out } \\
\mathrm{T}\left({ }^{\circ} \mathrm{C}\right)\end{array}$ & $\begin{array}{c}\text { JW P } \\
(\text { bar })\end{array}$ & $\begin{array}{c}\text { JW Mass } \\
\text { Flow } \\
\text { (ton/h) }\end{array}$ \\
\hline \hline 100 & 74 & 15,37 & 17,03 & 186,68 & 171,65 & 79,98 & 3,08 & 220,45 \\
85 & 71,2 & 14,85 & 15,04 & 179,8 & 153,1 & 79,97 & 3,1 & 223,79 \\
75 & 67,1 & 13,98 & 12,59 & 175,08 & 131,43 & 80 & 3,13 & 224,6 \\
60 & 57,7 & 11,9 & 7,86 & 167,77 & 96,32 & 79,96 & 3,15 & 228,29 \\
\hline
\end{tabular}

While Table 1 includes general information of simulated ship and main engine, Table 2 shows engine speed, ship speed, mean effective power of the engine, exhaust (Exh) stack temperature and mass flow rate, jacket water (JW) temperature, pressure and mass flow rate of the main engine for each lever position.

Simulator keeps seawater (SW) inlet temperature, pressure and mass flow rate constant across the simulations as $20^{\circ} \mathrm{C}, 4.29 \mathrm{bar}, 335.24 \mathrm{t} / \mathrm{h}$ respectively.

Specific fuel consumption and contents of exhaust gas have significant importance on GHG emissions of ship and its main engine. Simulator provides NOx, SOx concentration data in the exhaust. CO2 concentration in the exhaust is not provided by the simulator. Nevertheless, $\mathrm{CO} 2$ could be evaluated qualitatively by SFC due to their correlation. Table 3 shows specific fuel consumption and exhaust gas contents for each lever position.

Beside the lever position as parameter, second parameter is chosen as organic fluid. With respect to the main engine data, 7 organic compound selected from previous works as cyclohexane [18], isohexane [28], R141b [29], R601 and R601a [30], R113 [9], lastly most frequently used R245fa [10, 11, 17, 18, 28-31]. All of them were evaluated in EES software [32] with respect to working interval of temperature and pressure. Then, 4 out of all are selected as suitable fluids to be employed in the system. Table 4 shows selected organic fluids, their ASHRAE safety value [33], type of fluid, pump and turbine outlet pressures. Pressures are kept constant throughout analyses.

According to ASHRAE, A and B denote lower and higher toxicity respectively while increasing numbers represent increasing flammability [33]. Type of fluid could be described as the slope of saturation vapor curve on T-s diagram of the fluid as positive and negative slope represent wet and dry respectively while slope around zero represent isentropic fluid [10].

Table 3. Specific fuel consumption and exhaust gas content of the main engine

\begin{tabular}{cccc}
\hline Ahead Lever $(\%)$ & SFC $(\mathrm{g} / \mathrm{kWh})$ & NOx $(\mathrm{g} / \mathrm{kWh})$ & $\mathrm{SOx}(\mathrm{g} / \mathrm{kWh})$ \\
\hline \hline 100 & 184,44 & 15,14 & 12,91 \\
85 & 181,03 & 15,23 & 12,68 \\
75 & 181,42 & 11,47 & 12,7 \\
60 & 193,5 & 11,29 & 13,54 \\
\hline
\end{tabular}

Table 4. Organic fluids and their conditions

\begin{tabular}{ccccc}
\hline Fluid & ASHRAE Safety & Type & Pump Out P (bar) & Turbine Out P (bar) \\
\hline \hline R113 & A1 & Dry & 10,8 & 0,5 \\
R245FA & B1 & Dry & 24 & 1,5 \\
R601 & A3 & Dry & 17 & 1,2 \\
R601A & A3 & Dry & 20 & 1,5 \\
\hline
\end{tabular}


Table 5. Assumed real and unavoidable component conditions

\begin{tabular}{|c|c|c|}
\hline \multirow[t]{2}{*}{ Component } & \multicolumn{2}{|c|}{ Conditions } \\
\hline & Real & Unavoidable \\
\hline 1 Pump & $\eta=0,8$ & $\eta=0,9$ \\
\hline \multirow[t]{3}{*}{2 Preheater } & $\Delta P_{12}=0,2$ bar & $\Delta P_{12}=0,1$ bar \\
\hline & $\Delta P_{89}=0,2 b a r$ & $\Delta P_{89}=0,1$ bar \\
\hline & $\Delta T_{\text {Min }}=8^{\circ} \mathrm{C}$ & $\Delta T_{\text {Min }}=3{ }^{\circ} \mathrm{C}$ \\
\hline \multirow[t]{2}{*}{3 Regenerator } & $\Delta P_{12}=0,2$ bar & $\Delta P_{12}=0,05 \mathrm{bar}$ \\
\hline & $\Delta P_{78}=0,05$ bar & $\Delta P_{78}=0,02$ bar \\
\hline \multirow[t]{3}{*}{4 Economizer } & $\Delta P_{43}=0,15$ bar & $\Delta P_{32}=0,1 \mathrm{bar}$ \\
\hline & $\Delta P_{1514}=0.01 \mathrm{bar}$ & $\Delta P_{1312}=0.003 \mathrm{bar}$ \\
\hline & $x_{3}=0^{\dagger}$ & $x_{3}=0^{\dagger}$ \\
\hline \multirow[t]{5}{*}{5 Evaporator } & $\eta_{P}=0,8$ & $\eta_{P}=0,9$ \\
\hline & $\Delta P_{\text {Circ }}=0,1$ bar & $\Delta P_{\text {Circ }}=0,06$ bar \\
\hline & $\Delta P_{1413}=0.005$ bar & $\Delta P_{1413}=0.003$ bar \\
\hline & $\Delta T_{A p p}=3{ }^{\circ} \mathrm{C}$ & $\Delta T_{A p p}=1{ }^{\circ} \mathrm{C}$ \\
\hline & $x_{5}=1^{\dagger}$ & $x_{5}=1^{\dagger}$ \\
\hline \multirow[t]{3}{*}{6 Superheater } & $\Delta P_{65}=0,15 \mathrm{bar}$ & $\Delta P_{65}=0.08 \mathrm{bar}$ \\
\hline & $\Delta P_{1312}=0.005$ bar & $\Delta P_{1312}=0.003 \mathrm{bar}$ \\
\hline & $\Delta T_{\text {Min }}=8^{\circ} \mathrm{C}$ & $\Delta T_{\text {Min }}=3{ }^{\circ} \mathrm{C}$ \\
\hline 7 Turbine & $\eta_{T}=0,9$ & $\eta_{T}=0,92$ \\
\hline \multirow[t]{2}{*}{8 Condenser } & $\Delta P_{89}=0,02 \mathrm{bar}$ & $\Delta P_{89}=0,01$ bar \\
\hline & $\Delta P_{1716}=0,3 \mathrm{bar}$ & $\Delta P_{1716}=0,1 \mathrm{bar}$ \\
\hline
\end{tabular}

After decision of conditions and parameters, real and unavoidable conditions of components are needed to be described for the application of energy, exergy and advanced exergy analyses.

It is difficult to find data on components, which are used to form ORC, all data is assumed considering expert opinion and operating conditions. Cycle data could be found in Table 5

\section{ANALYSIS}

By using information given in Table 5, real cycles are designed. Temperature of exhaust stack after economizer is fixed at $160^{\circ} \mathrm{C}$ to avoid low temperature corrosion risk [30]. That restriction will give the highest possible waste heat harvesting opportunity. Power output of the turbine is noted for each cycle to be used in other created cycles.

Secondly, unavoidable cycles are created with respect to constant power outputs taken from real cycle. Thus, mass flow rate and exhaust stack temperature are let to float to fulfill the power output. It should be noted that after unavoidable conditions are applied, exhaust stack temperature is calculated above $160^{\circ} \mathrm{C}$. Unavoidable exergy destructions of components are determined by exergy analysis of each cycle.

With respect to lever position and organic compound parameters and their combinations, organic Rankine cycles are created. Energy and mass conversation laws are applied. Exergy and advanced exergy analyses are executed for all cycles and all components with respect to equations given in Table 6 .

\section{RESULTS AND DISCUSSION}

As it may be seen on Figure 2, applying energy analysis to all cycles which are combination of 4 different lever positions and 4 different organic fluids has revealed that maximum net power output is achieved at $100 \%$ lever position for all fluids. And for all lever positions, R113 has the highest net power outputs. Other three fluids have slightly different net power outputs. But minimum net power belongs to R601. R601 a has slightly higher $(0.42 \mathrm{~kW})$ net power output than R245fa at $100 \%$ lever, however at other lever positions R245fa is higher.

Maximum energy efficiency is also the highest for all fluids at $100 \%$ lever position. Similar with the net power output, energy efficiencies are the highest for R113 for all lever positions. The trends of efficiencies are 
similar for three of fluids R113, R601, R601a and efficiencies are almost the same for R601 and R601a. As it can be seen on figure 2, while all efficiencies rise with the increase of lever position, R245fa has approximately

Table 6. Energy balance and exergy analysis equations

\begin{tabular}{lccc}
\hline Component & Energy Balance & \multicolumn{2}{c}{ Exergy Analysis } \\
\cline { 3 - 4 } & & $\dot{E} x_{F}$ & $\dot{E} x_{P}$ \\
\hline \hline Pump & $\dot{W}_{P}=\dot{m}_{1}\left(h_{1}-h_{9}\right)$ & $\dot{W} x_{P}$ & $\dot{E} x_{9}$ \\
Preheater & $\dot{m}_{1}\left(h_{2}-h_{1}\right)=\dot{m}_{10}\left(h_{10}-h_{11}\right)$ & $\dot{E} x_{10}-\dot{E} x_{11}$ & $\dot{E} x_{2}-\dot{E} x_{1}$ \\
Regenerator & $\dot{m}_{3}\left(h_{2}-h_{3}\right)=\dot{m}_{7}\left(h_{7}-h_{8}\right)$ & $\dot{E} x_{7}-\dot{E} x_{8}$ & $E x_{3}-\dot{E} x_{2}$ \\
Economizer & $\dot{m}_{3}\left(h_{4}-h_{3}\right)=\dot{m}_{14}\left(h_{14}-h_{15}\right)$ & $\dot{E} x_{14}-\dot{E} x_{15}$ & $\dot{E} x_{4}-\dot{E} x_{3}$ \\
Evaporator & $\dot{m}_{4}\left(h_{5}-h_{4}\right)=\dot{m}_{13}\left(h_{13}-h_{14}\right)$ & $\dot{E} x_{13}-\dot{E} x_{14}$ & $\dot{E} x_{5}-\dot{E} x_{4}$ \\
Superheater & $\dot{m}_{6}\left(h_{6}-h_{5}\right)=\dot{m}_{12}\left(h_{12}-h_{13}\right)$ & $\dot{E} x_{12}-\dot{E} x_{13}$ & $\dot{E} x_{6}-\dot{E} x_{5}$ \\
Turbine & $\dot{W}_{T}=\dot{m}_{6} h_{6}-\dot{m}_{7} h_{7}$ & $\dot{E} x_{6}-\dot{E} x_{7}$ & $\dot{W_{T}}$ \\
Condenser & $\dot{m}_{8}\left(h_{8}-h_{9}\right)=\dot{m}_{16}\left(h_{17}-h_{16}\right)$ & $E x_{8}-\dot{E} x_{9}$ & $E x_{17}-\dot{E} x_{16}$ \\
\hline
\end{tabular}

constant first law efficiency starting from $75 \%$ of lever position. A detailed inspection on R245fa revealed that, the only fact is the change in mass flow rate of the fluid, enthalpies and entropies are nearly identical. Finally, it is obvious that none of the fluids or lever positions combinations have managed to cross the $20 \%$ efficiency border, but R113 has surpassed other fluids by means of both power output and efficiency. Hence, energy analysis reveals that the best fluid for this designed system is R113 for all lever positions.

All exergy rates of fuel and destruction have the same trend that is decreasing with the decreasing of lever position as it can be seen on Figure 3. Exergy rate of fuel is the highest for R245fa for all lever positions. The lowest is R601, which is slightly lower than R601a. Organic Rankine cycle total exergy rates of fuel for all fluids are $640 \mathrm{~kW}, 435 \mathrm{~kW}, 300 \mathrm{~kW}$ and $131 \mathrm{~kW}$ for $100 \%, 85 \%, 75 \%$ and $60 \%$ lever positions respectively.

It can be observed from Figure 3 that trends of exergy destruction rates are decreasing with lowering the lever position similar with exergy rate of fuel trend. The highest amount of exergy destruction belongs to R245fa. However minimum exergy destruction happened in R113. Exergy destruction rates of R601 and R601a are almost same. Organic Rankine cycle total exergy destruction rates for all fluids are $248 \mathrm{~kW}, 185 \mathrm{~kW}, 137 \mathrm{~kW}$ and $74 \mathrm{~kW}$ for $100 \%, 85 \%, 75 \%$, and $60 \%$ of lever positions respectively. Exergy efficiencies of all cycles have descending

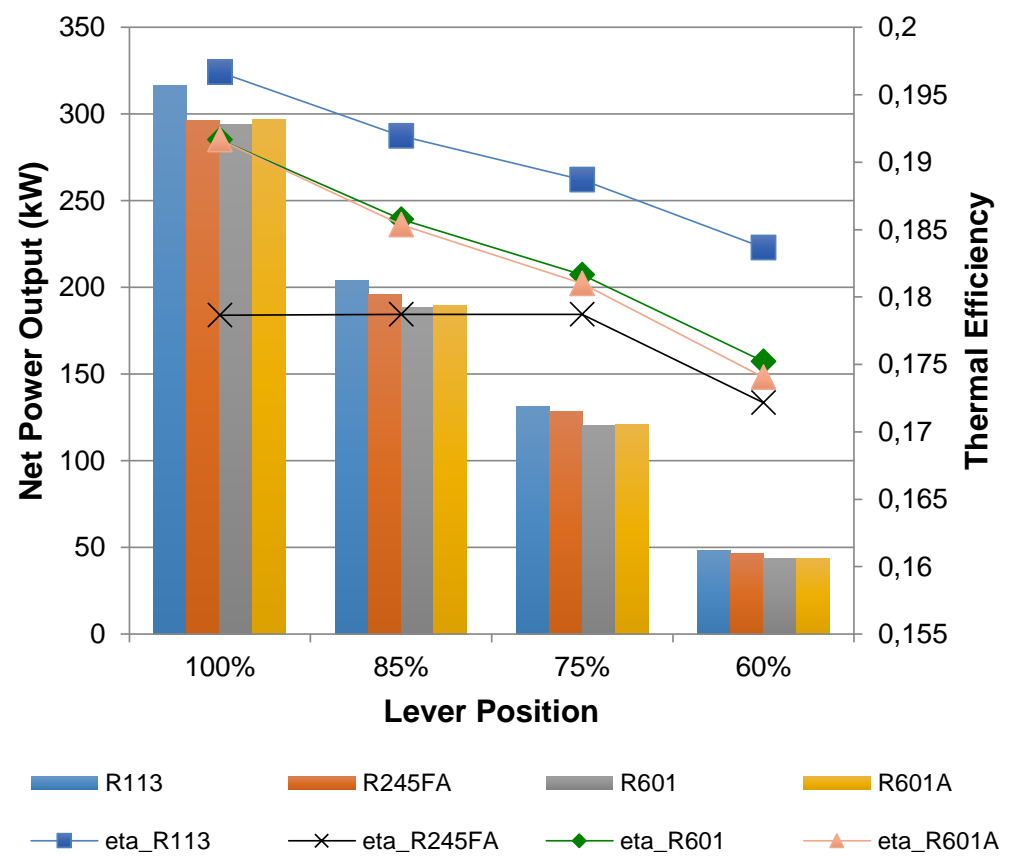


Figure 2. Energy efficiency and net power output of cycles

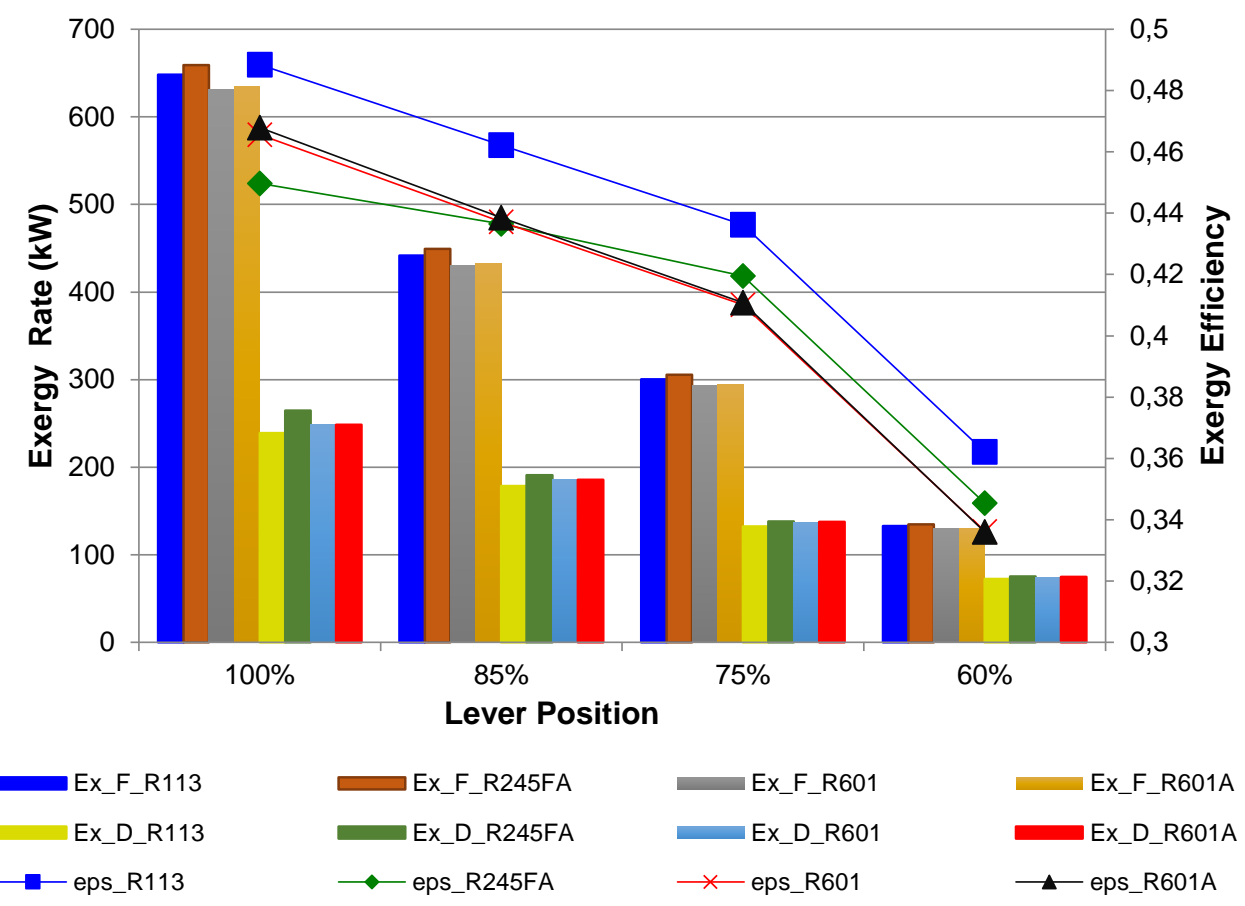

Figure 3. Overall exergy efficiency, exergy rate of fuel and exergy destruction of all cycles

trend by lever positions. Exergy efficiency slope is steeper between 75 and $60 \%$ when compared to the others. Maximum exergy efficiencies belong to R113 for all lever positions. R601 and R601a values are almost the same at all points. For lever position 100\%, R601 and R601a efficiencies are higher than R245fa. These three cross at $85 \%$ lever, then, R245fa has higher efficiency than other two fluids.

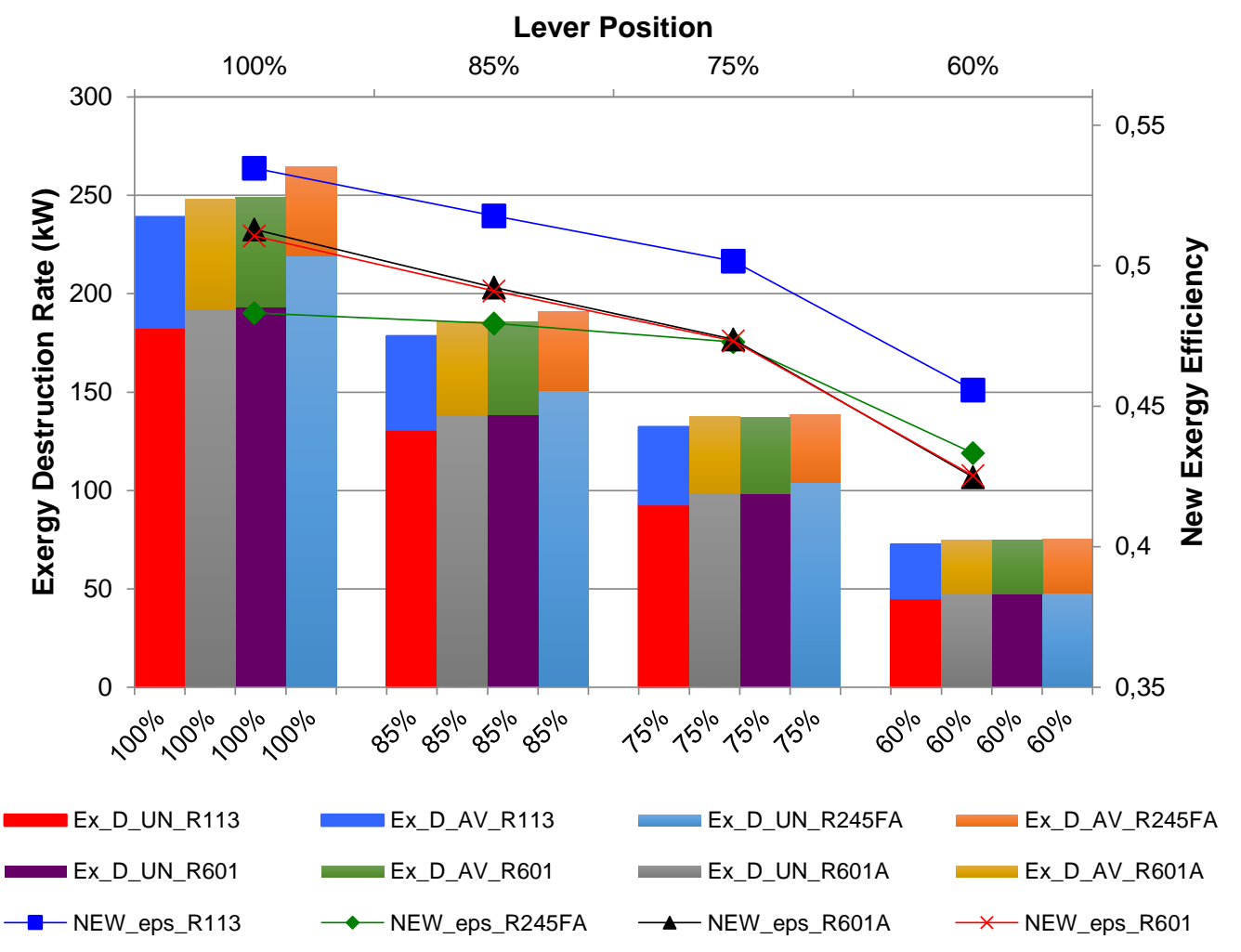


Figure 4. Overall new exergy efficiency, avoidable and unavoidable exergy destruction of all cycles

Results of splitting total exergy destructions of cycles into avoidable and unavoidable parts are shown in Figure 4. The highest unavoidable exergy destruction belongs to R245fa as its total exergy destruction rate for all lever positions. Unavoidable parts of exergy destructions are almost identical for R601 and 601a. R113 has the lowest unavoidable exergy destruction among all.

Avoidable exergy destruction rates are approximately same for R113, R601 and R601a as seen on Figure 4. Among them, the highest is R113. However, R245fa has the lowest avoidable exergy destruction rate for $100 \%$, $85 \%, 75 \%$ lever positions but similar with others for $60 \%$ lever. R113 has the highest new exergy efficiencies for all lever positions same as exergy efficiency. However, the highest exergy efficiency was around 0.48 in Figure 3 , new exergy efficiency revealed that 0.53 efficiency is achievable for R113 at $100 \%$ lever, which is $10 \%$ improvement on exergy efficiency. Even the lowest efficiency for R113 at $60 \%$ lever was around 0.36 , new exergy efficiency showed that it could be around 0.46 and the improvement of efficiency is $28 \%$. New exergy efficiencies of R601 and R601a are almost identical as their exergy efficiencies and lower than R113. But their 100\% lever efficiency was around 0.47 in Figure 3, and new exergy efficiency is 0.51 as in Figure 4. Also, their lowest efficiency was around 0.33 , new efficiency is around 0.42 . The lowest new exergy efficiency belongs to R245fa for $100 \%$ and $85 \%$ lever positions. It has similar value with R601 and R601a at $75 \%$ lever position. At $60 \%$ lever position, R245fa has higher new exergy efficiency than R601 and R601a.

Energy, exergy and advanced exergy analyses revealed that the best fluid for the designed ORC is R113 with respect to the highest net power output; energy, exergy and new exergy efficiencies; lowest exergy and unavoidable exergy destruction rates.

Figure 5 shows exergy destruction ratios of components for R113 by proportioning exergy destruction of each component to total exergy destruction rate of $238.991 \mathrm{~kW}, 178.436 \mathrm{~kW}, 132.239 \mathrm{~kW}, 72.511 \mathrm{~kW}$ for $100 \%$, $85 \%, 75 \%, 60 \%$ lever position respectively. Economizer has the highest share of exergy destruction rate among all components and pump is the lowest. Exergy analysis says that improvement efforts should be focused on economizer first for all lever positions. There are fluctuations on component exergy destruction ratios for lever positions. For pump, preheater, regenerator, evaporator, turbine have decreasing exergy destruction ratios related to decreasing of lever position. However, economizer and superheater exergy destruction ratios increase with the decrease of lever positions.

For $100 \%$ and $85 \%$ lever positions, exergy analysis revealed that improvement efforts should be on economizer, evaporator, condenser, superheater, turbine, preheater, regenerator and pump respectively. For $75 \%$ lever position, preheater has more exergy destruction ratio than turbine and all other components have same ranking with $100 \%$ and $85 \%$. For $60 \%$ lever position, efforts should be focused on economizer, evaporator, superheater, condenser, preheater, turbine, regenerator, and pump respectively.

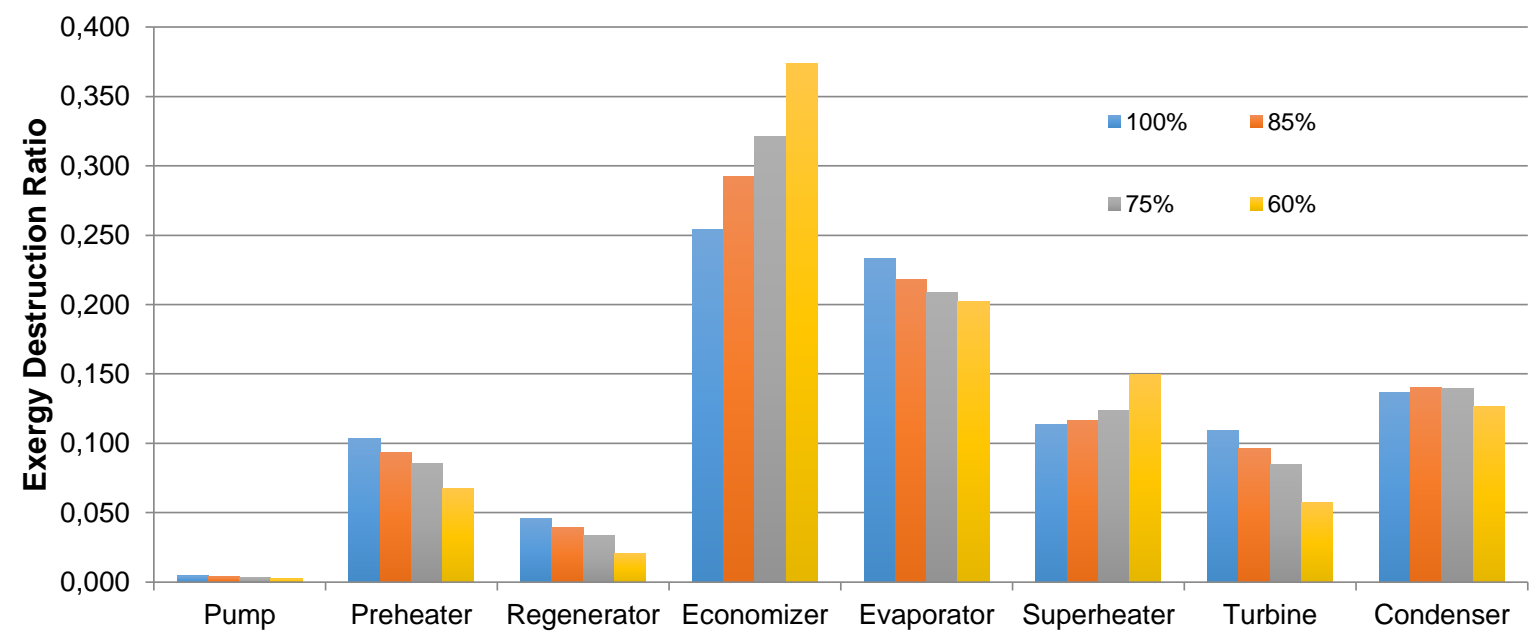

Figure 5. Exergy destruction ratios of components with respect to lever positions for R113 


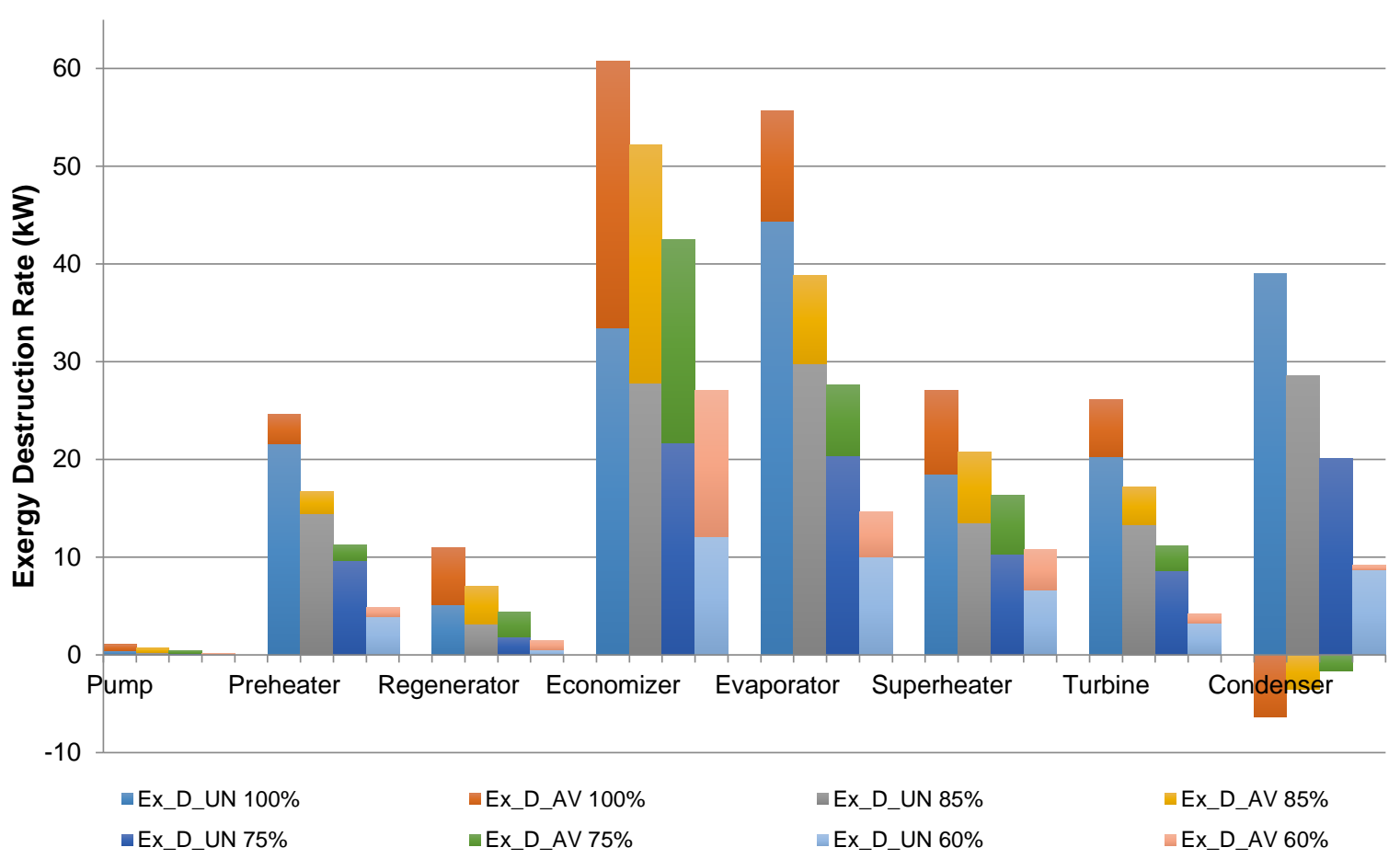

Figure 6. Avoidable and Unavoidable Parts of Exergy destruction rate for all components and all lever positions

In Figure 6, avoidable and unavoidable parts of exergy destruction are given for each component and lever position.

Avoidable and unavoidable parts of exergy destructions of components decrease with the decreasing of lever position as seen on Figure 6. Pump has the lowest avoidable and unavoidable exergy destruction as expected. The highest amount of avoidable exergy destruction rate belongs to Economizer for all lever positions. With respect to the avoidable exergy destruction rate of components, it may be said that improvement efforts should be focused on economizer, evaporator, superheater, turbine, regenerator, preheater, pump and condenser respectively for $100 \%$ lever position. At $85 \%$ and $75 \%$, it is listed as economizer, evaporator, superheater, regenerator, turbine, preheater, pump and condenser respectively. Economizer, evaporator, superheater, regenerator, turbine, preheater, condenser and pump may be improved in sequence for $60 \%$ lever position.

Also, a different result has been observed at $100 \%, 85 \%$, and $75 \%$ lever positions for avoidable exergy destruction rate of condenser as in Figure 6. They are calculated as negative values. This situation means that unavoidable conditions do not result better for condenser. Keeping turbine outlet pressure constant, and unavoidable conditions of components as brings extra cooling load for condenser to cool organic fluid. Hence, its unavoidable exergy destruction part is calculated more than real exergy destruction. This extra load could be due to one, two or all components in the system. Nevertheless, the extra cooling load situation is removed at $60 \%$ lever position and avoidable exergy destruction rate has been positive.

Figure 7 shows exergy efficiency and new exergy efficiency of each component for all lever positions. New exergy efficiency actually shows the improvement potential of the exergy efficiency of investigated component. New exergy efficiencies are all higher than exergy efficiencies of the components excluding condenser. This represents that components have high opportunity of improvement. Having negative avoidable exergy destruction rate increases the required exergy rate of fuel to achieve same amount of product exergy rate, so new exergy efficiency is lower than exergy efficiency.

Figure 8 reveals specific fuel consumption, NOx, and SOx contents of the exhaust gas before and after ORC applied. A detailed look may reveal improvement has been achieved for all lever positions while main engine speed, ship speed, fuel consumption are constant. It may be said that adding ORC could lower climate change effect of the ship due to decreasing SFC and GHGs. Power output of ship engine is increased by the power output of ORC. Shaft generator is being used on-board. As seen on Figure 8, comparing shaft generator and ORC power 
output shows that power output of ORC is higher than shaft generator for $100 \%$ lever position. That means while ship sails at navigational full ahead, which is the most of the voyage, there will not be a need for shaft generator

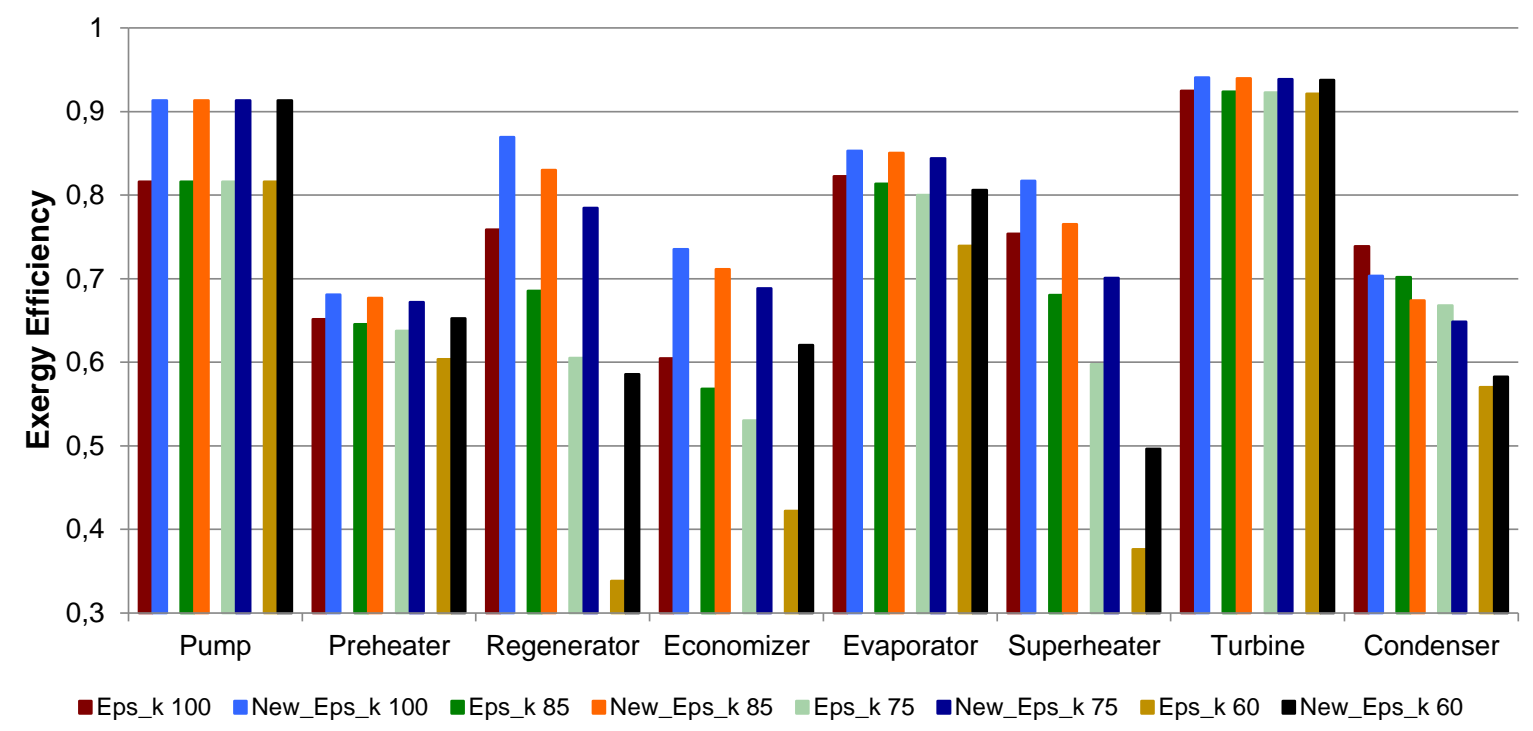

Figure 7. Exergy and new exergy efficiencies of components for all lever positions

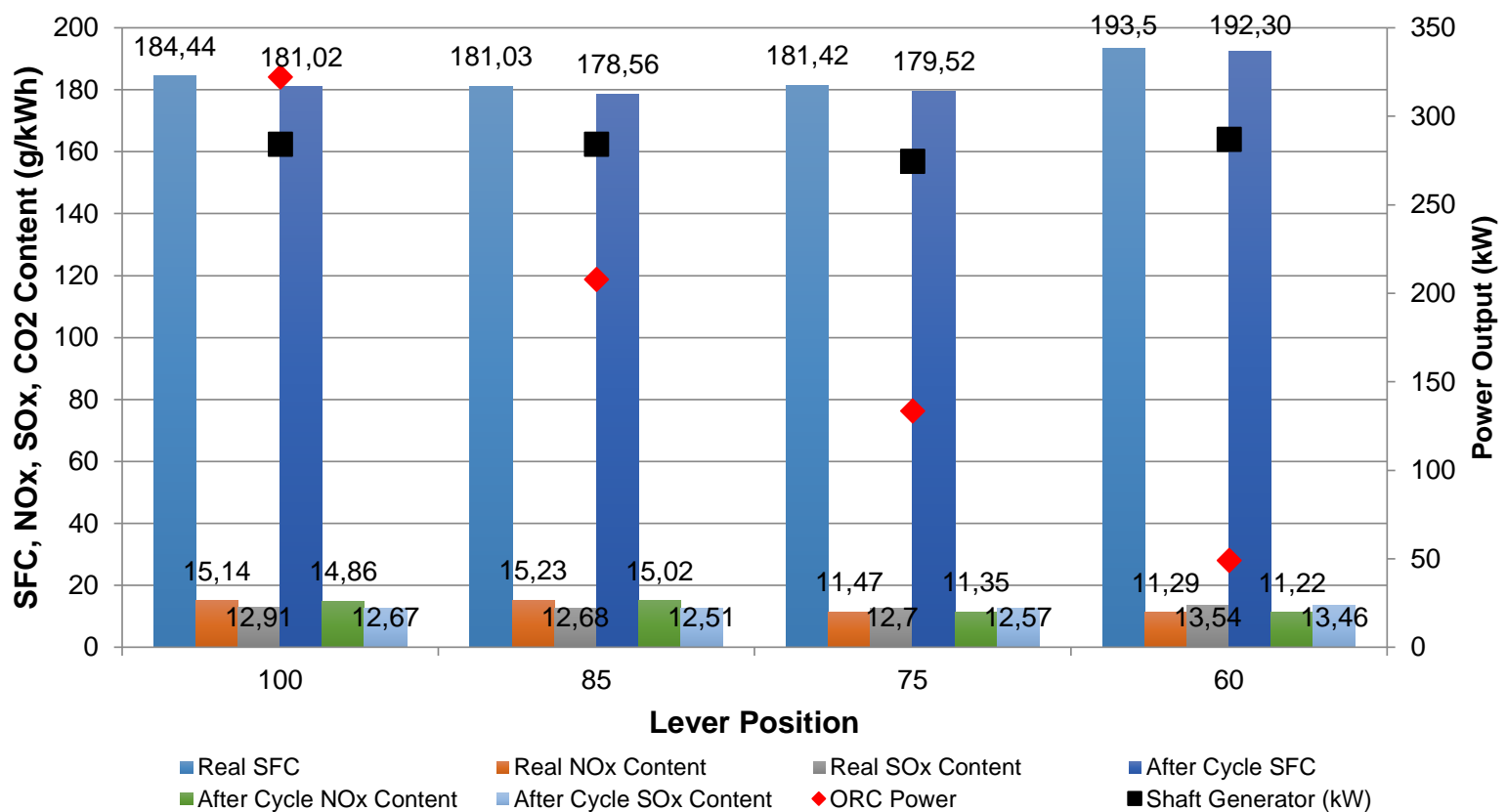

Figure 8. Specific fuel consumption, NOx, SOx contents before and after ORC; shaft generator and ORC power outputs

to fulfil electricity demand on-board. Thus, propeller could directly use all power that is produced by main engine. Even if propeller requires more power, ORC power output would be added to shaft by PTI/PTO gearbox.

\section{CONCLUSION}

In this paper, an organic Rankine cycle system has been designed and applied to exhaust stack of a general cargo ship with five-cylinder two-stroke main engine. Different ahead lever positions, different organic fluids and their combinations have been investigated and analyzed with the help of energy, exergy and advanced exergy analyses. 
Changes of regenerator temperature difference, pump and turbine output pressure lead system instability and cause errors for each cycle. Hence these values are kept constant and determined to be the most favorable conditions.

Energy, exergy and advanced exergy analyses have revealed that the best fluid for ORC system is R113 with respect to the highest net power output, lowest exergy destruction, energy, exergy and new exergy efficiencies. It is also the most suitable fluid with lower toxicity and flammability among others. Also it is observed that new exergy efficiency shows the improvement potential of the exergy efficiency of investigated component.

A ship sails mostly on navigational full (100\%) lever position. On that condition, exergy analysis suggested that improvement efforts should be focused on economizer, evaporator, condenser, superheater, turbine, preheater, regenerator and pump respectively. However, advanced exergy analysis has shown that focus should be on economizer, evaporator, superheater, turbine, regenerator, preheater, pump and condenser respectively.

Improvements are observed on specific fuel consumption, NOx, and SOx emission of the main engine between $0.62 \%$ and $1.9 \%$. Also, at navigational full condition, electricity demand could be fulfilled by ORC power output. Hence, need of shaft generator is decreased for other lever positions.

Future work will be conducted to consider the conditions and problems listed below:

1. Negative avoidable exergy destruction of condenser has shown that interactions among system components and overall system should be investigated to reveal effects of components on investigated component. Hence, detailed advanced exergy analysis with endogenous and exogenous exergy destruction rates should be calculated and evaluated.

2. Suitability and safety conditions of the organic fluids may be considered with more fluids.

3. Also, exergoeconomic and advanced exergoeconomic analyses must be carried out to evaluate system components whether the system is feasible.

4. All fluids are chosen with respect to literature and it is seen that all used fluids in this work are dry organic fluids. So, a system without superheater and regenerator could be considered, investigated and evaluated by means of exergy, advanced exergy analyses and compared the system investigated in this study.

\section{NOMENCLATURE}

$\begin{array}{ll}\text { ASHRAE: } & \text { American Society of Heating, Refrigerating and Air-Conditioning Engineers } \\ \text { CO2: } & \text { Carbon Dioxide } \\ \text { Ex: } & \text { Exergy Rate } \\ \text { Exh: } & \text { Exhaust } \\ \text { GHG: } & \text { Green House Gas } \\ \text { h: } & \text { Enthalpy } \\ \text { JW: } & \text { Jacket Water } \\ \text { MCR: } & \text { Maximum Continuous Rating } \\ \dot{m}: & \text { Mass Flow Rate } \\ \text { NOx: } & \text { Nitrogen Oxide Compounds } \\ \text { ORC: } & \text { Organic Rankine Cycle } \\ \text { P: } & \text { Pressure } \\ \dot{Q}: & \text { Heat } \\ \text { s: } & \text { Entropy } \\ \text { SFC: } & \text { Specific Fuel Consumption } \\ \text { SOx: } & \text { Sulfur Oxide Compounds } \\ \text { SW: } & \text { Seawater } \\ \text { T: } & \text { Temperature } \\ \dot{W}: & \text { Power } \\ \text { WHR } & \text { Waste Heat Recovery } \\ \text { y*: } & \text { Exergy Destruction Ratio } \\ \varepsilon: & \text { Exergy Efficiency } \\ \eta: & \text { Energy Efficiency }\end{array}$




$\begin{array}{ll}\text { Subscripts: } & \\ \text { 0: } & \text { Reference Condition } \\ \text { App: } & \text { Approach } \\ \text { Circ: } & \text { Circulation } \\ \text { D: } & \text { Destruction } \\ \text { F: } & \text { Fuel } \\ \text { j: } & \text { Stream } \\ \text { k: } & \text { Component } \\ \text { Min: } & \text { Minimum } \\ \text { P: } & \text { Product } \\ \text { Th: } & \text { Theoretical } \\ \text { tot: } & \text { Total } \\ & \\ \text { Superscripts: } & \\ +: & \text { New } \\ \text { AV: } & \text { Avoidable } \\ \text { UN: } & \text { Unavoidable }\end{array}$

\section{REFERENCES}

[1] Pachauri, R.K., et al., Climate Change 2014: Synthesis Report. Contribution of Working Groups I, II and III to the Fifth Assessment Report of the Intergovernmental Panel on Climate Change. 2014.

[2] Smith, T., et al., Third IMO GHG Study 2014. International Maritime Organization (IMO), London, 2014.

[3] Baldi, F. and C. Gabrielii, A feasibility analysis of waste heat recovery systems for marine applications. Energy, 2015. 80: p. 654-665.

[4] MAN Diesel\&Turbo, Waste heat recovery system (WHRS) for reduction of fuel consumption, emissions and EEDI, in Copenhagen, Denmark. 2014b, MAN Diesel, Augsburg, Germany.

[5] Alvik, S., et al., Pathways to low carbon shipping-abatement potential towards 2030. 2009.

[6] Shu, G., et al., A review of waste heat recovery on two-stroke IC engine aboard ships. Renewable and Sustainable Energy Reviews, 2013. 19: p. 385-401.

[7] Wärtsilä, Solution for merchant vessels, W.r. Corporation, Editor. 2010.

[8] MAN Diesel\&Turbo, Thermo efficiency system for reduction of fuel consumption and CO2 emission. 2014a, MAN Diesel, Augsburg, Germany: Kopenhagen, Denmark.

[9] Sprouse III, C. and C. Depcik, Review of organic Rankine cycles for internal combustion engine exhaust waste heat recovery. Applied Thermal Engineering, 2013. 51(1-2): p. 711-722.

[10] Chen, H., D.Y. Goswami, and E.K. Stefanakos, A review of thermodynamic cycles and working fluids for the conversion of low-grade heat. Renewable and Sustainable Energy Reviews, 2010. 14(9): p. 30593067.

[11] Tumen Ozdil, N.F., M.R. Segmen, and A. Tantekin, Thermodynamic analysis of an Organic Rankine Cycle (ORC) based on industrial data. Applied Thermal Engineering, 2015. 91: p. 43-52.

[12] Bejan, A., M.J. Moran, and G. Tsatsaronis, Thermal design and optimization. 1996: Wiley. com.

[13] Dincer, I. and M.A. Rosen, Exergy (Second Edition): Energy, Environment and Sustainable Development. 2013: Elsevier. 576.

[14] Baldi, F., et al. Energy and exergy analysis of ship energy systems-the case study of a chemical tanker. in 27th ECOS, International Conference on Efficiency, Cost, Optimization, Simulation and Environmental Impact of Energy Systems. 2014.

[15] Baldi, F., et al. Energy and exergy analysis of a cruise ship. in The 28th ECOS, International Conference on Efficiency, Cost, Optimization, Simulation and Environmental Impact of Energy Systems. 2015.

[16] Marty, P., et al. Exergy analysis of complex ship energy systems. in 7th International Exergy, Energy and Environment Symposium. 2015. Valenciennes, France. 
[17] Yang, M.-H. and R.-H. Yeh, Analyzing the optimization of an organic Rankine cycle system for recovering waste heat from a large marine engine containing a cooling water system. Energy Conversion and Management, 2014. 88: p. 999-1010.

[18] Song, J., Y. Song, and C.-w. Gu, Thermodynamic analysis and performance optimization of an Organic Rankine Cycle (ORC) waste heat recovery system for marine diesel engines. Energy, 2015. 82: p. 976985.

[19] Wang, Z., et al., Exergetic Cost Analysis of Marine Diesel Engine Waste Heat Recovery System Based on Matrix Model Thermo-economics, in Advances in Material Science, Mechanical Engineering and Manufacturing, Q.J. Gao, Editor. 2013. p. 566-570.

[20] Morosuk, T. and G. Tsatsaronis, A new approach to the exergy analysis of absorption refrigeration machines. Energy, 2008. 33(6): p. 890-907.

[21] Kotas, T.J., The exergy method of thermal plant analysis. 1985: Butterworth Publishers,Stoneham, MA. Medium: X; Size: Pages: 344.

[22] Koroglu, T. and O.S. Sogut. Advanced exergy analysis of a Marine Diesel Engine waste heat recovery system. in International Conference on Shipping in Changing Climates. 2015. Glasgow: University of Stratclyde.

[23] Tsatsaronis, G. and M.-H. Park, On avoidable and unavoidable exergy destructions and investment costs in thermal systems. Energy Conversion and Management, 2002. 43(9): p. 1259-1270.

[24] Gong, S. and K. Goni Boulama, Parametric study of an absorption refrigeration machine using advanced exergy analysis. Energy, 2014. 76: p. 453-467.

[25] Vučković, G.D., et al., Advanced exergy analysis and exergoeconomic performance evaluation of thermal processes in an existing industrial plant. Energy Conversion and Management, 2014. 85: p. 655-662.

[26] Cengel, Y.A. and M.A. Boles, Thermodynamics : an engineering approach. 2015, New York: McGraw Hill.

[27] STEAG, EBSILON®Professional. 2015, STEAG Energy Services GmbH: Essen, Germany.

[28] Larsen, U., et al., Design and optimisation of organic Rankine cycles for waste heat recovery in marine applications using the principles of natural selection. Energy, 2013. 55: p. 803-812.

[29] Tian, H., et al., Fluids and parameters optimization for the organic Rankine cycles (ORCs) used in exhaust heat recovery of Internal Combustion Engine (ICE). Energy, 2012. 47(1): p. 125-136.

[30] Deniz, C., Thermodynamic and Environmental Analysis of Low-Grade Waste Heat Recovery System for a Ship Power Plant. International Journal of Energy Science, 2015. 5(1): p. 23-34.

[31] Panesar, A.S., et al., Working fluid selection for a subcritical bottoming cycle applied to a high exhaust gas recirculation engine. Energy, 2013. 60: p. 388-400.

[32] F-Chart_Software. Enginnering Equation Solver. 2015 [cited 2015 10/08/15]; Available from: http://www.fchart.com/ees/.

[33] ASHRAE, Designation and Safety Classification of Refrigerants ANSI/ASHRAE Standard 34-2013. 2013. 